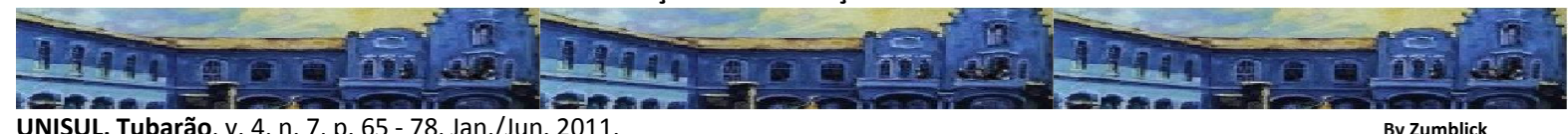

\title{
DA ÉTICA DO DEVER-SER A ÉTICA DO DIÁLOGO
}

\author{
Wellington Lima Amorim ${ }^{1}$ \\ Sérgio Ricardo Gacki ${ }^{2}$
}

\section{RESUMO}

Este artigo tem o objetivo de demonstrar a aparente contradição do pensamento hegeliano. A tentativa de Hegel é unir a substância de Espinosa com o "Eu" de Kant, ou seja, necessidade e contingência. Como sabemos este projeto é inacabado, e um operador modal, ou seja, um dever-ser cósmico mais fraco que o dever-ser kantiano perpassando todo o sistema, não resolve esta questão. Refletir sobre esta problemática nos conduz ao conceito de ética do diálogo em Gadamer sendo possível nos levar em direção a uma estrutura ética intersubjetiva. Portanto, deve-se postular tal questão "ab initio" para justificar o caminho da presente argumentação, que ao reconhecer essa dimensão de encontro do humano, defende o diálogo hermenêutico como cerne dessa estrutura ética. Em Gadamer existe um convite para um reconhecimento do que esta em jogo: o diálogo. No horizonte da perspectiva hermenêutica, o diálogo constitui-se em uma práxis, uma postura fundamentalmente ética.

Palavras-chave: Hermenêutica. Ética. Dever-ser

\section{THE ETHICS OF MUST BE TOWARD ETHICS OF DIALOGUE}

\begin{abstract}
This paper intend to demonstrate the apparent contradiction of Hegelian thought. Hegel's attempt is to unite with the substance of Spinoza and whit the "I free" of Kant, in other words, necessity and contingency. As we know this project is unfinished, and a modal operator, ie, a "must be" cosmic being weaker than the "must be" Kantian permeating the whole system, does not resolve this question.To reflect about this problematic leads us to the concept of ethical dialogue in Gadamer and you can take us toward an intersubjective ethical structure. Therefore, one must postulate such question "ab initio" to justify the way of this argument, recognizing that this dimension of the human meeting, advocates the dialogue as a hermeneutical core of this ethical structure. In Gadamer there is an invitation to a recognition of what is at stake: the dialogue. On the horizon of hermeneutic perspective, the dialogue is in a praxis, a fundamentally ethical stance.
\end{abstract}

Key-words: Hermeneutics. Ethics. Must-be.

\footnotetext{
${ }^{1}$ Dr em Ciências Humanas - Prof. Universidade Federal do Maranhão - Endereço postal: Rua Aloísio Lima 1653 - Iningá - Teresina - Piaui - CEP: 64049-830 - E-mail: wellington.amorim@gmail.com

${ }^{2} \mathrm{Dr}$ em Educação - Prof. Complexo Superior de Ensino de Cachoeirinha do RS - Endereço postal: Rua Blumenau, 798 - Santo André - São Leopoldo - RS - CEP: 93044-020 - E-mail: srgacki@hotmail.com
} 


\section{INTRODUÇÃO}

Este artigo será desenvolvido em um primeiro momento a partir da análise históricofilosófico dos conceitos de Contingência, Liberdade e Dever-ser em Hegel. Está análise busca apresentar os principais pressupostos do pensamento hegeliano a partir da Ética de Espinosa, Fichte e a Doutrina da Ciência, Schelling e o primeiro esboço de sistema realizado conjuntamente com Hegel e o eu livre expresso na Crítica da Razão Prática em Kant. Como sabemos o sistema hegeliano se apresenta necessitário e um operador modal, um dever-ser cósmico, que atravesse todo o sistema não resolve esta problemática filosófica.

Esta revisão bibliográfica busca uma saída possível para esta questão através do pensamento de Gadamer e os conceitos de intersubjetividade e subjetividade. $\mathrm{O}$ pensamento de Gadamer percorre a tradição filosófica ocidental para demonstrar a impossibilidade de uma diç̧ão absoluta, mas diferentemente do pensamento hegeliano, se apresenta em múltiplas faces, uma realidade que está em constante transformação, forjando uma nova forma de se ver o real.

\section{Contingência, Liberdade e Dever-ser}

Segundo alguns autores, a lógica hegeliana é a tentativa da dicção absoluta, ou seja, da dedução total da realidade. De acordo com a ideia do próprio Hegel, a tarefa principal do sistema seria encarar o momento negativo, não para permanecer nele, mas para superar a negatividade e buscar a síntese mediante a negação da negação. A consequência dessa postura leva ao puro necessitarismo sistemático, reduzindo o espaço da contingência até eliminá-la por completo e assegurando de modo definitivo a diç̧ão absoluta ${ }^{3}$, ou a dedução de toda a realidade.

A lógica de Hegel inspira-se e baseia-se no sistema neoplatônico de Espinosa e no projeto de Filosofia proposto por Fichte. O projeto hegeliano tem influência direta de Fichte,

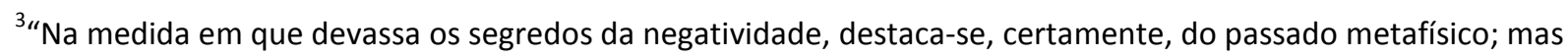
não menos certo é que Hegel só se afeiçoa à contradição para melhor destituí-la de seu poder e fazer com que sirva a uma motivação que permanece nele fiel à Metafísica. Hegel quer sobrepujar um entrave sempre presente na Metafísica, sem abandonar, entretanto, o ideal metafísico da identidade e da dicção absoluta". (BORNHEIM, 1971).
} 
a partir de sua importante obra Sobre o Conceito da Doutrina da Ciência (Über den Begriff der Wissenschaftslehre). (FICHTE, 1971, p. 27ss.). Fichte pretendia dar conta de toda e qualquer filosofia futura, ou seja, de deduzir toda a realidade desde as causas primeiras até a multiplicidade das coisas; isto é o que se denomina atualmente de projeto de sistema do idealismo alemão.

Dessa forma, Hegel e Schelling elaboram o primeiro projeto de sistema sob a total influência de Fichte. Mas quando se busca o denominador comum entre esses mestres, despontam também Kant e Espinosa. (SPINOZA, 1954, p. 30). Para compreender o problema da contingência em Hegel, é preciso levar em consideração dois aspectos: a) o sujeito livre de Kant; b) o conceito de substância de Espinosa. A conciliação de ambos constitui o projeto de Filosofia de Hegel, como ele o expressa no Prefácio da Fenomenologia do Espírito: "Na minha opinião, que só pode ser justificada pelo sistema, o ponto central consiste em pensar e expressar a verdade não só como substância, mas também como sujeito" ${ }^{4}$.

Que significa o sujeito livre em Kant? Para ele, o sujeito livre não é uma substância ou res extensa, conforme Descartes (DESCARTES, 1953) imaginava, mas espírito, ou seja, res cogitans. Todas as representações, idéias, imagens e os sentimentos, diferentes de um indivíduo para outro, são sempre acompanhados de um eu penso universal e, por isso transcendental, consciente de si mesmo, idêntico à consciência e dotado da estrutura composta das formas puras da sensibilidade, ou seja, espaço e tempo, e das formas do entendimento, ou seja, as doze categorias.

E qual o conceito de substância para Espinosa? Tudo é governado por uma necessidade lógica absoluta. A ordem da natureza é geométrica. Nada há que ocorra por acaso no mundo físico. Tudo o que acontece é uma manifestação da natureza imutável de Deus. Conforme esse pensamento, a ideia de substância é a de um ser que se identifica inteiramente com a natureza e com Deus, Deus sive natura. As coisas acontecem sempre mecanicamente. O mecanismo é a razão que movimenta e organiza o mundo, que é a natureza. Essa natureza é divina. "Da necessidade da natureza divina podem resultar coisas infinitas em número infinito de modos, isto é, tudo o que pode cair sob um intelecto divino". (ESPINOSA, 1983, p. 92).

\footnotetext{
${ }^{4}$ HEGEL, Friedrich. vol. 3, PhG . p. 22-23: "Es kommt nach meiner Einsicht, welche sich nur durch die Darstellung des Systems selbst rechtfertigen muss, alles darauf an, das Wahre nicht als Substanz, sondern ebensosehr als Subjekt aufzufassen und darzustellen".
} 
Segundo o filósofo, a substância divina existe necessariamente. Cada coisa que existe é um modo, uma manifestação da substância divina. 'Natura naturans' é a própria substância, Deus em sua essência infinita; 'Natura naturata' são os modos e as manifestações da essência divina: o mundo. A natureza naturante, isto é, Deus, prolonga-se na matéria como modo de manifestação de Deus; este basta a si mesmo no processo de automanifestação contínua como Natureza Criadora de si mesma. Já que toda a natureza decorre necessariamente da essência de Deus, não existem imperfeições nela. Assim, na natureza, o poder pelo qual as coisas existem e atuam não é outro senão o poder eterno de Deus. Existir, ser e agir são a mesma coisa, e tudo o que existe é necessário. Não há contingência no universo. "Na natureza nada existe de contingente; antes, tudo é determinado pela necessidade da natureza divina a existir e a agir de modo certo". (ESPINOSA, 1983, Prop. XXIII).

Para Espinosa, tudo o que existe depende da substância divina; sem ela nada pode ser concebido. Entretanto a natureza produz, desdobra-se e atua de diferentes modos. Assim, segundo o conceito de substância na natureza, tudo é bom, pois Deus é bom. O que se vê no mundo concreto não é o necessário, mas o contingente. Mesmo esse ser contingente, porém, pertence à substância única, uma vez que nada é estranho à Natureza divina, tudo está previsto no poder da substância criadora.

Esse modo de pensar conduz à visão de natureza que é apenas um sistema de causas mecânicas. A multiplicidade dos modos (de Deus) não é contrária à unidade, pois é subsumida no ser e no agir pela ordem unitária de Deus. Por outro lado, as emoções não estão separadas da natureza, são naturais e, consequentemente, sujeitas às leis da natureza. A natureza (Deus ou substância) age em virtude da necessidade pela qual existe. Não há fins na natureza que lhe sejam externos, apenas a necessidade intrínseca.

Para que o homem se compreenda e entenda os fatos e as situações em que se envolve, é necessário relacionar os acontecimentos com a idéia de substância divina, que é Deus, já que tudo é parte deste Deus. Desse modo, para manter o equilíbrio, o homem deve obedecer a essa ordem necessária. Entretanto, o homem é apenas uma parte da natureza, e esta, evidentemente, não está restrita às necessidades humanas, mas há infinitas outras leis que se estendem à totalidade da natureza. O homem não é causa necessária de sua existência; logo, pode sofrer mudanças exteriores em sua natureza. A natureza é pensante, e esse pensar é a própria essência de Deus. Os atributos de Deus se fundamentam na unidade. 
A natureza é uma; qualquer coisa, qualquer atributo de Deus resulta necessariamente de sua natureza absoluta. Assim, qualquer que seja a concepção de natureza, seja como extensão ou pensamento, sempre se encontra uma só ordem, uma única união de causas, uma só realidade: essa realidade é o mesmo que Deus.

Como Deus é a própria natureza, esta é perfeitíssima e boa, porque o poder da natureza é o próprio poder de Deus; o direito natural é o poder que Deus exerce sobre todas as coisas. É somente pela liberdade absoluta desse poder que todo ser da natureza tem a capacidade de existir e de agir. Deus, entretanto, não é criador, pois isso faria supor um limite ao seu ser. Ele é a manifestação necessária da essência. É sua própria causa e substância essencial, absoluta, única, infinita, a partir da qual tudo está determinado, tanto em sua essência quanto em sua existência. Ou seja, Deus se manifesta no existente, na totalidade da natureza, e esta manifesta a totalidade da existência e a potência de Deus como causa eficiente e imanente.

A existência do mundo é a manifestação eterna, infinita e absoluta da essência de Deus. "A Natureza inteira é um só indivíduo cujas partes, isto é, todos os corpos, variam de infinitas maneiras, sem qualquer mudança do indivíduo na sua totalidade" ${ }^{5}$. A introdução sobre a Filosofia de Espinosa contribui sobremaneira para o entendimento do núcleo do problema da contingência, porque só assim é possível localizar a contingência no sistema hegeliano. Mas, para isso, analisa-se também o conceito de contingência e de liberdade na Filosofia de Kant:

O conceito de liberdade em Hegel significa, portanto, autonomia no sentido da primeira definição que Kant dá de liberdade na Crítica da razão prática, mas não significa a livre escolha entre alternativas contingentes, que são por iguais possíveis, como Kant expressa e formula na segunda definição, o que é ser livre. (CIRNE-LIMA, 1993, p. 105).

O projeto de Hegel pretende realizar a conciliação entre o conceito de substância de Espinosa e o sujeito livre de Kant. Nesse sentido, a tarefa da Filosofia é assumir o absoluto não somente como substância única, mas também como sujeito livre. Hegel, porém, privilegiou o lado espinosista, descuidando-se da relevância do conceito de liberdade para a filosofia kantiana. Hegel não tratou como deveria o importante conceito de livre-arbítrio. Cabe lembrar que o conceito de contingência é vital para se entender a questão do livre-

\footnotetext{
${ }^{5}$ ESPINOSA. Baruch. Ibidem, Ética. Prop. XIII, escólio.
} 
arbítrio. Em Hegel, o livre-arbítrio não aparece com a clareza necessária, ou seja, como a possibilidade de livre-escolha entre as diversas alternativas igualmente possíveis. Isso ocorre principalmente quando, na síntese da necessidade absoluta, a contingência parece se dissolver.

Para expressar, portanto, uma necessidade que contém sempre contingência, é necessário utilizar outro termo e outro conceito. Cirne-Lima sugere que se traduza necessidade absoluta por um dever-ser cósmico. A grande lei vigente no Universo é um dever-ser que cria ordem sem que se instale um determinismo férreo; um dever-ser que, perpassando todo o Universo, é uma necessidade mais fraca que a necessidade dos lógicos, é uma necessidade que, exatamente por ser mais fraca, pode ser considerada uma lei universalíssima. A necessidade das grandes leis do ser e do pensar é, assim, um dever-ser. 0 próprio Princípio de Não-Contradição deve ser formulado como um dever-ser.

A necessidade absoluta que é um categoria sintética, na qual necessidade e contingência estão superadas e guardadas, expressa uma conciliacão de ambos os polos antes opostos e, por isso, tem que ser compreendida, não como um "sernecessário", mas como um "dever-ser". (CIRNE-LIMA, 1993, p. 63).

Precisamos entender com exatidão em que consiste esse dever-ser - Sollen - sobre o qual Aristóteles, usando como exemplo o Princípio de Não-Contradição, afirma:

\begin{abstract}
Analogamente, ainda que o mesmo ente seja mil vezes um homem e não-homem, ao responder a pergunta sobre se ele é um homem o adversário não $d$ e $v$ e acrescentar que é também, simultaneamente, um não-homem, a menos que seja obrigado a acrescentar todos os outros acidentes, tudo que é sujeito é ou não é, e, se assim fizer, não estará observando as regras da argumentação. (MAFFESOLI, 1994, p. 1994).
\end{abstract}

Entender o sistema hegeliano regido por um deve-ser cósmico, mesmo que seja compreendido como uma necessidade fraca trará sempre problemas para a contingência, que quer ocupar o seu espaço. Michel Maffesoli, (MAFFESOLI, 1994), deixa clara a sua insatisfação quando afirma que, ao determinar teoricamente o conceito de dever-ser, este conduz as nossas atitudes às piores tiranias, aos totalitarismos, "convém, aliás, observar [...] que o moralismo não é característica de um único partido particular [...] os exemplos de Stalin e Hitler bem o provam". (MAFFESOLI, 1994, p. 31). O primeiro filósofo moderno que distinguiu claramente os conceitos de ser e dever-ser foi David Hume. Esse pensador 
demonstrou que as proposições normativas não podem ser derivadas das descritivas. Que isso significa? Canto-Sperber explica com clareza:

\begin{abstract}
A dicotomia entre o ato e o valor significa que todo raciocínio que faz aparecer o termo "dever" na conclusão, quando ele não figura em nenhum lugar nas premissas, não é válido. Assim, a inferência de "as sociedades humanas não são igualitárias" para "as sociedades humanas devem ser não-igualitárias" não é válida. (CANTO-SPERBER, 2004, p. 74-75).
\end{abstract}

Observa-se claramente que não podemos deduzir enunciados normativos a partir de enunciados descritivos. Ficam evidentes, nesse sentido, as conseqüências desastrosas que podem surgir a esse respeito. A própria Canto Sperber (2004) afirma:

\begin{abstract}
Elas são exemplares abstrações do erro de raciocínio denunciado por David Hume, erro que consiste em passar de proposicões que aduzem o que é a proposicão que dizem o que deve-ser, ou o que G. E. Moore chamou de "sofisma naturalista". Pelo fato de o ser humano tender espontaneamente a buscar prazer e a evitar a dor, não significa que isso seja bom e que seja assim ou deva ser assim. (2004,p. 70).
\end{abstract}

Outro exemplo foi o que ocorreu com Hebert Spencer ao fazer uma interpretação errônea de Hume. Spencer acreditava ser um erro intervir em favor dos despossuídos, visto que, se na natureza existe um processo de seleção natural, seria saudável e de grande utilidade para as sociedades humanas admitir a existência de um processo de seleção natural, onde os mais aptos teriam a garantia de sobrevivência. Como resolver esse problema da oposição entre necessidade e liberdade? A liberdade deve ser absorvida pela necessidade? Durante o autodesenvolvimento do Absoluto ocorre - no fim da Lógica da Essência -, segundo Hegel, uma relação absoluta que ele denomina de 'ação recíproca'. "A causa não tem somente um efeito, mas no efeito ela está como causa em relação a si mesma". (HEGEL, 1968, p. 238). Em outras palavras, o absoluto é causa sui, ele se movimenta e determina a si mesmo. A primazia da necessidade que exclui a contingência e a liberdade acabou? Não, isso somente ocorrerá se o operador modal que perpassar o Universo e o sistema, que é o mais universal de todos, for o conceito de phronésis, que abrirá espaços para a contingência. Isso só ocorrerá tanto na ontologia do Universo como na Filosofia do Espírito mediante uma nova compreensão, deixando de pensar a realidade regida por um Sollen, um dever-ser. 
Embora Hegel, em muitos textos, tenha combatido a idéia de um dever-ser como princípio universalíssimo; embora Hegel tenha em vários lugares criticado o dever-ser como uma forma deficiente da necessidade da idéia, o resultado final de uma análise cuidadosa da dialética das modalidades mostra que o operador modal universalíssimo é uma necessidade absoluta. Ora, tal necessidade só se encontra no dever-ser. Hegel, ao que parece, nunca percebeu que o resultado a que chegou na dialética das modalidades, ao invés de afastar qualquer dever-ser de seu sistema, o transforma no principal operador modal do sistema. Como sair desta cilada?

\section{Intersubjetividade e subjetividade}

Neste sentido, buscando sair desta encruzilhada é que o pensamento de Gadamer contribui significativamente para a nossa problemática ao prestar contas de um trajeto histórico e conceitual da Filosofia Ocidental que busca esclarecer que " equivocadamente encontra-se por detrás do conceito de intersubjetividade o conceito de subjetividade ". (GADAMER, 2007. p. 11). Assim, o conceito de intersubjetividade somente torna-se possível diante da anterior explicitação do conceito de subjetividade. Aquilo que deu à palavra subjectum, e ao conceito de subjetividade a aparente obviedade que hoje compartilhamos, diz Gadamer, "foi o fato de o "sujeito" visar a algo assim como auto-relação, reflexividade e egoidade". (GADAMER, 2007. p. 11). Não se percebe isso na palavra grega hypokeimenon da qual ela é tradução, que significa aquilo que se encontra inalteravelmente à base da mudança de todas as transformações. Ainda temos as traduções latinas de hypokeimenon: substantia e subjectum. Por intermédio deste conceito pode-se concluir que os sujeitos são basilares para o acontecer do processo intersubjetivo. Aristóteles introduz esse conceito com relação à natureza: "Daquilo que, junto a uma coisa, acontece na natureza como algo que ocorre ora de uma maneira ora de outra, ele distingue a coisa mesma junto à qual tudo acontece desse ou daquele modo." (GADAMER, 2007. p. 11).

Diante da metafísica aristotélica da substância Gadamer pergunta como o conceito moderno de sujeito e de subjetividade pôde retirar dessa orientação fundamental a sua própria aplicação particular. A resposta está no cogito me cogitare, tendo em vista ser a ele atribuído o primado do conhecimento enquanto fundamento inabalável que possui consistência frente a qualquer dúvida. O cogito torna-se a substância de todas as nossas 
representações, possibilitando o desenvolvimento do conceito de subjetividade, levado por Kant ao reconhecer a função da subjetividade na síntese transcendental da percepção, que precisa poder acompanhar todas as nossas representações e lhes empresta unidade, conforme nos lembra Gadamer.

A questão do sentido consubstancia-se em um fundamento vital, em um elemento existencial que vem por muito tempo preocupando a filosofia. A teia de eventos que permite ao homem a tomada de consciência de sua forma existencial e elevar a questão do sentido ao patamar de objeto de estudos sistemáticos. Cabe lembrar, que os defensores da narrativa pós-moderna muitas vezes confundem "sentido" com "utilitarismo", afinal, o sentido, hermeneuticamente falando, tem caráter ontológico. Mas este é um objetivo que quase sempre cai no velho círculo vicioso da disputa moral. Nietzsche indaga:

Sob que condições inventou-se o homem aqueles juízos de valor, bom e mau? E que valor têm eles mesmos? Obstruíram ou favoreceram até agora o prosperar da humanidade? São um signo de estado de indigência, de empobrecimento, de degeneração da vida? (NIETZSCHE, 1998, p.5).

Como propõe Nietzsche na Primeira Dissertação da Genealogia da Moral, é fundamental que seja questionada a validade da moral vigente, revisitando sua genealogia com vistas a dinâmica e metamorfose da moral, que se transmuta a todo o momento que Ihe favorece. O "bom" ou o que é bom, podem ser conceitos problemáticos se forem reproduzidos como "coisa em si". Vive-se em um mundo que a nós é desconhecido, no qual buscamos exaustivamente aplicar as categorias que herdamos de nossos pais. Mas a verdade é que não conseguimos efetivamente nos compreender, como afirma Empoli. Gadamer descreve esta situação quando fala do "esquecimento daquilo que persiste". Parece que o ser humano vive a crise de seu recalque, porém, já acredita em sua própria falácia, e não quer reconhecer os sintomas. Precisamos de novos valores, conforme sentencia Nietzsche:

Enunciemo-la, esta nova exigência: necessitamos de uma crítica dos valores morais, o próprio valor desses valores deverá ser colocado em questão para isto é necessário um conhecimento das condições e circunstâncias nas quais nasceram, sob as quais se desenvolveram e se modificaram (moral como conseqüência, como sintoma, máscara, tartufice, doença, malentendido; mas também moral como causa, medicamento, estimulante, inibição, veneno), um conhecimento tal como até hoje nunca existiu nem foi desejado. (NIETZSCHE, 1998, p.5-6) 
A reconstrução conceitual da moral acaba por forjar um ethos. O movimento cambiante dos conceitos é impelido pelas forças que regem a sociedade e ditam o que é "a moral". É interessante começar esta reflexão orientada pela primazia da pergunta como nos ensinou o pensamento socrático-platônico. Para Gadamer a compreensão não se concebe como um processo subjetivo do homem em face de um objeto, mas sim como modo de ser do próprio homem. A hermenêutica neste horizonte assume o âmbito de postura filosófica, que entre outras questões, presta-se a avaliar a compreensão, como processo ontológico do homem. Ao mencionar a analítica temporal da existência humana, que Heidegger desenvolveu, Gadamer refere que seu antigo mestre mostrou convincentemente que a compreensão não é um modo de ser, entre outros modos de comportamento do sujeito, mas o modo de ser da própria pre-sença (Dasein).

Enfim, existe uma relação circular em que o processo de compreensão acontece. Os atributos da coisa compreendida interferem e movem os atributos daquele que compreende. Há uma dinâmica de mutações que só é possível no diálogo - já não somos mais quem éramos, mas não somos subsumidos, pois mantemos o horizonte de quem somos e é para onde voltamos. O outro é sempre algo externo e estranho - é sempre o outro. No movimento circular, sempre voltamos ao familiar - a nós mesmos. Fica a tarefa de mantermos o movimento, evitando tanto o dogmatismo, quanto a queda no puro relativismo.

O problema não é o método, mas as supostas pretensões metodológicas. E ainda, o cerne do problema, é a incapacidade de quem trabalha com métodos, de abrir mão destes quando já não são adequados para a abordagem das diversas questões. Tudo isso nos remete a revisar a intenção prévia no confronto com a vida; mais especificamente no encontro com o outro. Por outro lado, precisamos também reconhecer a intenção prévia como aquela que mantém a legitimidade e que protege o compreender da arbitrariedade das opiniões que defendem a pura relatividade.

Tal relativismo mostra-se através de um autoritarismo que paradoxalmente, poderia ser denominado como a "universalidade do relativo". Porém, não se trata de ingenuidade a postura de defender a inexistência de sentido, tendo em vista que esta tal relativização, pode não ser desinteressada, pelo contrário, pode servir a diversos interesses. A mediocridade, como asseverava Nietzsche, passou a ser a palavra definidora do mundo em 
que vivemos. A hermenêutica não pretende ser uma doutrina de métodos, mas oferece um horizonte para que ocorra a reflexão para além de sua autoconsciência metódica - para além de seus preconceitos.

O horizonte hermenêutico evidencia a partir da crítica ao cientificismo. Essa tarefa passa pelo desdobramento de conceitos fundamentais apresentados em Verdade e Método e é importante recorrer a Nietzsche para apresentar um exemplo paradigmático de enfrentamento da postura metodológica exacerbada na supervalorização da consciência. A consciência assim se desvela como apenas um recorte do real que eventualmente pode contribuir nas diversas situações da vida.

Para nos deixar atentos ao valor da ética hermenêutica, Gadamer demonstra que é impossível ignorar as diferenças radicais entre o saber ético e o saber técnico. Gadamer reivindica o acontecer da hermenêutica como filosofia prática. Assim temos o desdobramento e a justificativa da pontuação da filosofia prática enquanto acontecer ético, que examina e evidência de que o homem não dispõe de si mesmo, como o artesão dispõe de seu material.

A questão, portanto, é saber como distinguir o saber que se tem de si, como pessoa ética, do saber que se tem para fabricar alguma coisa. Aquele que sabe como fabricar alguma coisa conhece por isso um bem, e o conhece - conhece-o "para si" - de tal maneira que, quando lhe é dada a possibilidade, é capaz de passar efetivamente à execução. Aquele que toma uma decisão ética aprendeu alguma coisa. Graças à educação e à formação recebida, ele possui um conhecimento geral do que chamamos de comportamento justo e correto. A função da decisão ética consiste então em encontrar, numa situação concreta, o que é justo. Em outros termos, a decisão ética encontra-se ali para "ver" e colocar em ordem tudo o que comporta em uma situação concreta, (GADAMER, 1998, p. 51), - assim fica evidenciada a impossibilidade de uma ética aplicada.

Neste sentido, a distinção que tínhamos sobre o saber técnico e ético desaparece? A resposta a esta pergunta, como pode ser verificado, está novamente na análise aristotélica da phronesis, ou seja, uma técnica se aprende e pode ser esquecida; pode-se "perder" uma habilidade. Mas o saber ético nem se aprende, nem se esquece. Ele não é como o saber de uma profissão, que se pode escolher. Não se pode recusá-lo e escolher outro saber, pois, ao contrário, o sujeito da phronesis, o homem, se encontra desde já em "ação numa situação" 
e, assim, sempre obrigado a possuir um saber ético e a aplicá-lo segundo as exigências de sua situação concreta. (GADAMER, 1998, p. 52).

Por essa mesma razão, verificou-se que falar de "aplicação" é algo problemático, já que só se pode aplicar aquilo que já se possui. Ora, o saber ético não é nossa propriedade, como são as coisas de que dispomos e que podemos ou não usar. Assim, se é verdade que a imagem, que o homem forma de si mesmo, do que ele quer e deve ser, é constituída por idéias diretrizes como as de justiça e injustiça, coragem, solidariedade etc., admitir-se-á facilmente que há uma diferença entre essas idéias e aquelas que o artesão concebe ao preparar um plano para a execução de seu trabalho. Basta pensarmos, para confirmar tal diferença, na maneira pela qual temos consciência do que é "justo". O que é "justo" é totalmente relativo à situação ética em que nos encontramos. Não se pode afirmar de um modo geral e abstrato quais as ações que são justas e quais não o são, não existem ações justas "em si", independentemente da situação que as reclame. (GADAMER, 1998, p. 52).

Portanto, a crença quase religiosa em métodos, trata-se de um pensamento que como foi demonstrado conduz muitos pensadores a acreditar que na sua fala, além de esgotar o tema, garante-lhes, que a alteridade foi finalmente suprida. Nisto a hermenêutica é promissora, pois esclarece os limites. Pode-se concluir que dizer algo, em primeiro lugar, nunca esgota o tema. Para termos clareza desse processo precisamos revisitar a tradição da filosofia que nos aproxima da Paidéia e em alguns momentos articula questões da Bildung, por óbvio, não em defesa de uma retomada nos moldes iluministas, mas em um diálogo que busca a riqueza de sua contribuição, retomando a filosofia prática e a primazia da pergunta, mantendo um diálogo verdadeiramente hermenêutico com esta tradição. A hermenêutica de Gadamer está protegida do dogmatismo, pois se mantém em abertura dialógica com a tradição, fugindo do lugar comum e da postura meramente metodológica.

Fica evidenciado que a postura da ética do diálogo proposto por Gadamer configura-se como uma via para os homens se encontrarem e se respeitarem em suas diferenças, burlando o esquema metódico que crê na homogeneização do pensamento humano. O diálogo propõe outros caminhos, tanto no seu constante confronto com a "ilusão" do duplo viés na teoria e práxis, no enfrentamento " desses artigos de fé errados, transmitidos por herança, [que] acabaram por se tornar um tipo de fundo comum da espécie humana". (NIETZSCHE, 1978, p. 119). A hermenêutica trabalha na perspectiva da dimensão 
especulativa do lógos. Afirma que quem fala uma linguagem, mas que não entende nada mais além dela, não fala. Falar significa falar a alguém.

\section{CONCLUSÃO}

Este artigo analisou de um ponto de vista histórico-filosófico os conceitos de Contingência, Liberdade e Dever-ser em Hegel, buscando e apontar uma possível solução para o necessitarismo no sistema hegeliano através do pensamento de Gadamer.

Fez uma trajetória apontando para os principais pressupostos de Hegel: Espinosa, Fichte, Schelling e Kant. Demonstrou a que a solução dada por um Dever-ser, Sollen, perpassando todo o sistema, não oferece uma solução plausível para esta problemática filosófica.

Assim, foi necessário resgatar o pensamento de Gadamer e os conceitos de intersubjetividade e subjetividade. A importância do pensamento de Gadamer no decorrer deste texto, na tentativa de correção do sistema hegeliano, é feita quando Gadamer demonstra a impossibilidade de uma dicção absoluta, e reafirmando uma realidade multifacetada, em constante transformação.

\section{REFERÊNCIAS BIBLIOGRÁFICAS}

ARISTÓTELES. Metafísica. São Paulo: Abril Cultural, 1979.

BORNHEIM, Gerd. Sartre. Rio de Janeiro: Editora Perspectiva, 1971.

CANTO-SPERBER, Monique. Que devo fazer? A filosofia moral. São Leopoldo: UNISINOS, 2004.

CENCl, Ângelo; DALBOSCO, A. Claudio; MÜHL, Eldon Henrique (Org.). Sobre Filosofia e Educação: racionalidade, diversidade e formação pedagógica. Passo Fundo: Ed. Universidade de Passo Fundo, 2009.

CIRNE-LIMA, Carlos Roberto Velho. Sobre a contradição. Porto Alegre: Edipucrs, 1993.

DESCARTES, René. Oeuvres complètes. Paris: Gallimard, 1953.

ESPINOSA, Baruch. Ética. São Paulo: Abril Cultural, 1983.

SPINOZA, Baruch. Oeuvres complètes. Paris: Gallimard, 1954. 
EMPOLI, Giuliano. Hedonismo e Medo: o futuro brasileiro do mundo. Porto Alegre: Sulina, 2007.

FICHTE, Johann Gottlieb. Fichtes Werke. Berlin: de Gruyter, 1971.

GADAMER, Hans-Georg. Hermenêutica em retrospectiva - A virada hermenêutica (vol. II). Petrópolis, RJ: VOZES, 2007.

0 problema da consciência histórica. Pierre Fruchon (Org.). Tradução de Paulo César Duque Estrada. Rio de Janeiro: Fundação Getúlio Vargas, 1998.

HEGEL, Georg Wilhelm Friedrich. Ciencia de la lógica. 2aㅡ Ed. Buenos Aires: Solar, 1968.

MAFFESOLI, Michel. A sombra de Dionísio. Paris: Editora Zouk, 1994.

NIETZSCHE, Friedrich. A Gaia Ciência. 2a Ed. São Paulo: Abril Cultural, 1978.

NIETZSCHE, Friedrich. Genealogia da Moral. São Paulo: Companhia das Letras, 1998. 